\title{
X. IMPURITY CONTROL AND MATERIALS PHYSICS
}

\author{
M. ULRICKSON (PPPL), J. N. BROOKS (ANL), H. F. DYLLA (CEBAF), \\ R. J. GOLDSTON (PPPL), J. R. HAINES (McDonnell-Douglas), \\ D. N. HILL (LLNL), R. A. LANGLEY (ORNL), \\ G. H. NEILSON (ORNL), and K. L. WILSON (SNL)
}

\section{X.A. INTRODUCTION}

The design for the BPX power and particle handling system consists of a double-null (DN) poloidal divertor with an inner-wall bumper limiter. In addition, a substantial portion of the remainder of the inside of the torus is covered with graphite tiles to withstand high heat flux. In divertor operating modes, the diverted plasma is "swept" across the divertor plates to reduce the time-average heat loads on the plates. The poloidal divertor is designed both to provide access to $\mathrm{H}$-mode operation and to ensure high recycling in the divertor region, which minimizes impurity production and consequent contamination of the main plasma. The device is capable of both single-null (SN) and DN divertor operation. In addition, an inner bumper limiter is designed to provide an alternative to divertor operation. Additional toroidally and/or poloidally localized limiters are provided on the outboard wall for plasma startup and for protection of the radiofrequency (RF) antennas.

All of the plasma-facing components must withstand the high heat flux anticipated in BPX (ranging from levels comparable to present devices at $P_{f u s}=$ $100 \mathrm{MW}$ at $Q=5$, up to $\sim 2.5$ times that of present devices at $P_{f u s}=500 \mathrm{MW}$ ). Pyrolytic graphite has been chosen for the divertor plates because very high thermal conductivity can be obtaincd. All the plasmafacing components must be able to be removed and reinstalled using the BPX remote handling systems. The peak heat loads on the divertor during disruptions are also an important design consideration. These transient heat loads are much larger than those during normal operation. Another reason for choosing graphite as the plasma-facing material is that under extremely high heat loads, it sublimates rather than melting like most metals. In addition, the plasma energy losses due to impurity radiation are much lower with carbon than with higher $Z$ metals. However, graphite has a number of special properties, such as high retention for water and hydrogen, that must be considered in the design and operation of the experiment.

The distribution of plasma power on the first-wall components is discussed in Chap. IX. Power handling and the choice of material for the divertor plates and limiters is discussed in Sec. X.B. A discussion of surface temperature limits and erosion mechanisms is in
Sec. X.C. Wall conditioning and bakeout requirements form Sec. X.D. The effect of disruptions on the plasma-facing components follows in Sec. X.E. Finally, tritium retention and particle pumping issues related to the choice of graphite as the first-wall material are discussed.

\section{X.B. POWER haNDLING AND MATERIAL SELECTION}

The peak power load on the divertor plate was found to be in the range of $50 \mathrm{MW} / \mathrm{m}^{2}$ from the modeling using the B2 code (see Chap. IX). The profile of the heat flux on the divertor plate is also given by the B2 code. The heat flux is swept across the divertor plate during the high-power phase of the plasma discharge. Figure 10.1 shows an example of the time variation of the heat flux at a given point on the divertor plate as the plasma deposition profile is swept past. It has been found that a constant rate sweep does not give a constant surface temperature over the swept area. ${ }^{1}$ An optimal sweep that results in a uniform temperature over the swept area requires a slower sweep early in the burn phase and late in the burn

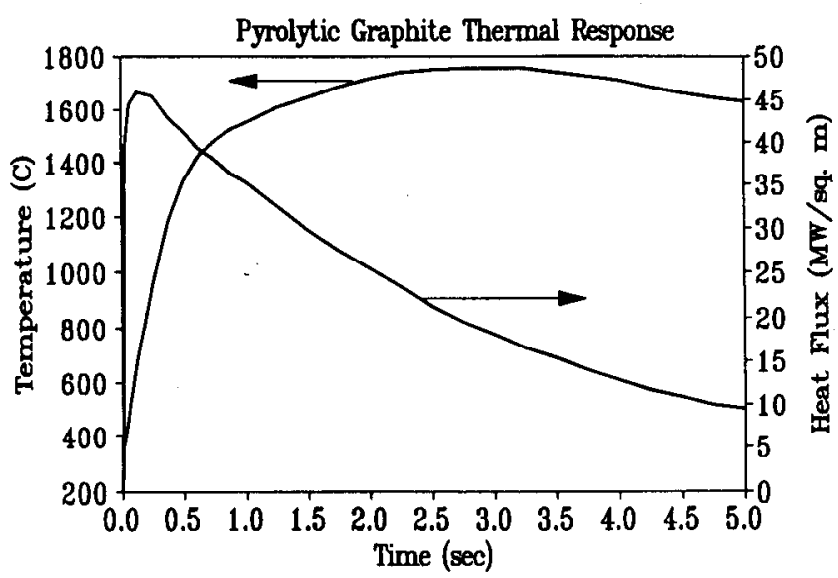

Fig. 10.1. The time variation of the power to a point on the divertor plate as the plasma is swept past. The resulting temperature of the surface of a pyrolytic graphite tile in response to the reference heat flux is also shown. 


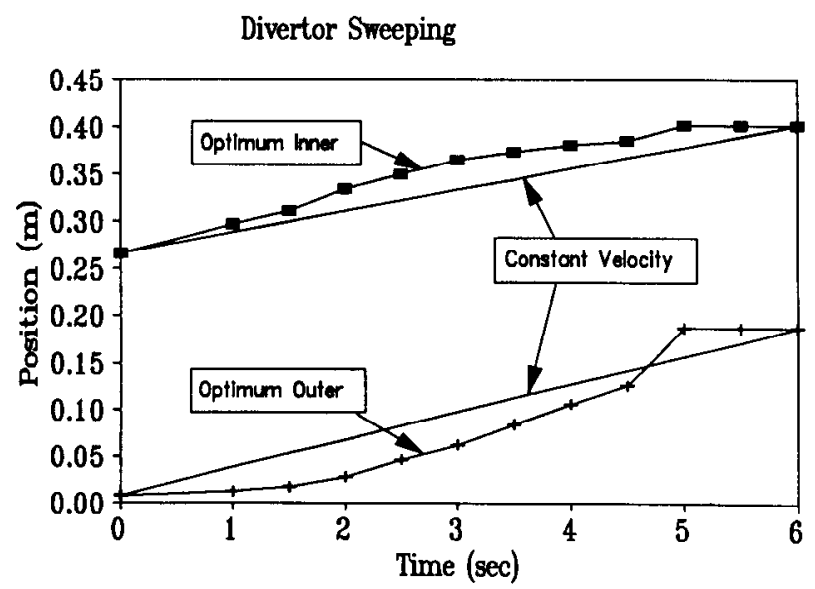

Fig. 10.2. The difference between the location of the separatrix field line on the divertor plate for a constant velocity sweep and the optimized sweep that gives a constant divertor tile surface temperature.

phase. ${ }^{1}$ The sweep must be slow early in the burn phase because plasma energy is building up as the RF power is applied. The sweep slows down at the end of the burn phase to allow time for the tiles at the end of burn to get as much energy as those at the beginning of burn. Figure 10.2 shows the optimal sweep compared with a constant velocity sweep.

The thermal response of a pyrolytic graphite divertor tile to the reference heat flux is shown in Fig. 10.1. The pyrolytic graphite assumed for the calculation had a thermal conductivity of $500 \mathrm{~W} / \mathrm{m} \cdot \mathrm{K}$ (at $300 \mathrm{~K}$ ). Pyrolytic graphite with a thermal conductivity as high as $1600 \mathrm{~W} / \mathrm{m} \cdot \mathrm{K}$ is available, but such materials are not available in sufficient quantity at reasonable cost to allow them to be considered in the design. Similar calculations have been done for a variety of other materials. The results are shown in Table 10.1. The results show that tungsten is the only other material that does not melt for the reference divertor heat flux and duration. However, tungsten is not a viable candidate because at the calculated surface temperature $\left(\sim 3000^{\circ} \mathrm{C}\right)$, its evaporation rate is $\sim 60 \mathrm{mg} / \mathrm{m}^{2}$. Such a high evaporation rate would cause too much plasma contamination. We conclude that a material having a thermal conductivity of at least $500 \mathrm{~W} / \mathrm{m} \cdot \mathrm{K}$ is required for the BPX divertor material. Similar analyses for the innerwall limiter show the minimum thermal conductivity for the limiter tile material to be $250 \mathrm{~W} / \mathrm{m} \cdot \mathrm{K}$.

Carbon-fiber composites (CFCs) have been found to be superior to fine-grained graphites (e.g., POCO graphite) on the TFTR Bumper Limiter. ${ }^{2}$ The TFTR CFC material (an FMI four-directional composite) is much less susceptible to damage from disruptions, has higher strength, and has slightly higher thermal conductivity. In general, both two- and three-directional
TABLE 10.1. The Thermal Response of Possible Alternate BPX Divertor Materials

\begin{tabular}{|l|c|c|}
\hline Material & $\begin{array}{c}\text { Maximum Surface } \\
\text { Temperature }\left({ }^{\circ} \mathrm{C}\right)\end{array}$ & Material Melts \\
\hline Pyrolytic Graphite $^{\mathrm{b}}$ & 1767 & No \\
\hline Tungsten & $3000^{\circ}$ & No \\
\hline Molybdenum & 2610 & Yes at $0.86 \mathrm{~s}$ \\
\hline Tantalum & 2996 & Yes at $0.60 \mathrm{~s}$ \\
\hline Beryllium & 1277 & Yes at $0.17 \mathrm{~s}$ \\
\hline
\end{tabular}

After $3.5 \mathrm{~s}$ of $\mathrm{P}_{\alpha}=100 \mathrm{MW}$.

'The reference material.

'At this temperature the evaporation rate is $60 \mathrm{mg} / \mathrm{m}^{2}$.

CFCs have a higher (almost two times) fatigue allowable (percentage of ultimate strength that can be used for multiple cycle stress applications) than fine-grained graphites. Recent developments in CFC technology and fabrication techniques have produced a one-directional CFC material that nearly equals the thermal conductivity of the reference pyrolytic graphite. We anticipate changing the reference divertor material to CFC if the development of these materials follows the present schedule. There are no commercially available CFC materials meeting the limiter thermal conductivity requirements. However, BPX research and development (R\&D) efforts have resulted in the fabrication of prototype materials that do meet our thermal conductivity requirements.

High-thermal-conductivity graphites rely on a very high degree of orientation of the crystal lattice. Neutron damage to the highly oriented crystal structure will scatter the phonons responsible for the thermal conductivity and reduce the thermal conductivity. This phenomenon has been observed ${ }^{3}$ in compressionannealed pyrolytic graphite at neutron fluences similar to those in BPX. The existing data are for a fission neutron energy spectrum and lower temperatures than we anticipate on BPX. Further R\&D is needed to determine the effect of fusion neutrons on the annealed pyrolytic graphite planned for use on BPX. We may or may not have to replace the divertor plate during the deuterium-tritium (D-T) phase of BPX operations because of this effect. There are no data on the neutron damage effects on the thermal conductivity of CFC materials. Samples of some CFC materials are being irradiated to determine the loss of conductivity of these materials. Irradiation of the carbon fibers used to make CFC materials show that the more highly oriented fibers (those with the highest thermal conductivity) suffer the least degradation. ${ }^{4}$ If this result is found 
for the composites, we will have another reason to change the baseline material to CFC from pyrolytic graphite.

\section{X.C. CARBON EROSION AND IMPURITY CONTROL}

The erosion and redeposition of carbon for the BPX divertor have been calculated using the REDEP code. $^{5}$ The REDEP code uses a Monte Carlo approach to estimate the erosion and redeposition of carbon from the divertor plates. The erosion rates are determined from a combination of physical sputtering, ${ }^{6}$ chemical erosion, ${ }^{7}$ radiation-enhanced sublimation, ${ }^{8,9}$ and thermal sublimation. ${ }^{10}$ The plasma conditions at the divertor plate were modeled using the B2 code, as discussed in Chap. IX. The background plasma was held fixed (only trace amounts of carbon were assumed, and carbon radiation did not change the heat flux) for the REDEP calculation. The plasma sheath was modeled using a dual exponential structure. ${ }^{11}$

Because of the high plasma density near the divertor plate, the mean-free-path for ionization of eroded carbon atoms is only $\sim 0.14 \mathrm{~mm}$. This greatly reduces the amount of carbon that can escape the region of high heat flux and deposit in cool regions, where a large amount of tritium is trapped. The average energy of a carbon atom returning to the plate is only $\frac{3}{2} k T_{e}$, instead of the $3 k T_{e}$ expected from sheath theory, because of the short mean-free-path. The lower energy of returning carbon ions reduces the carbon self-sputtering. These effects together result in the net erosion (erosion minus redeposition) being much less than the gross erosion (ignoring redeposition); i.e., there is a substantial amount of redeposition of carbon in the high-flux areas. In areas of high carbon redeposition, there is also a high flux of D-T neutrals. This codeposition of carbon and D-T results in trapping of D-T in the redeposited carbon layer. The amount of D-T trapped in the codeposited layers depends on the temperature of the deposition. ${ }^{12}$

The temperature dependence of the $\mathrm{D}-\mathrm{T} / \mathrm{C}$ ratio in the codeposited layer is shown in Fig. 10.3. The actual temperature distribution ${ }^{13}$ in the divertor tiles was taken into account for the D-T/C ratio in the redeposited film. The results of the calculation for several different maximum divertor surface temperatures are shown in Table 10.2 (Ref. 5). The trapped amounts are constant at high surface temperature because the majority of the trapped D-T is only in regions adjacent to the high heat flux regions because of the lack of trapping at high temperature in the codeposited film. Table 10.2 shows that the self-sputtering is $<1$ except at $2000^{\circ} \mathrm{C}$ with the result that runaway erosion (or the "carbon bloom" phenomenon ${ }^{2}$ ) is not anticipated at $1700^{\circ} \mathrm{C}$ (the allowed operating temperature for the divertor tiles). Figure 10.4 shows the eroded carbon flux [calculated by REDEP (Ref. 5)] and the incident D-T
Retention in Co-Deposited Layers

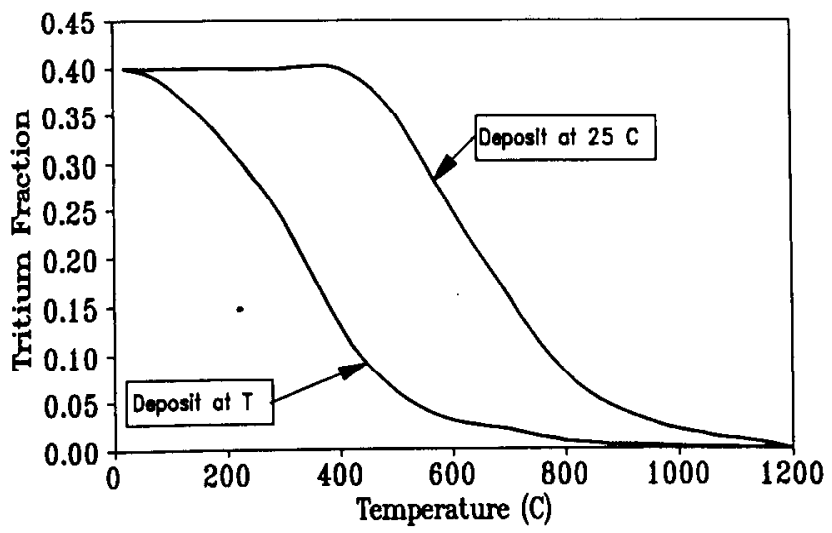

Fig. 10.3. The D-T/C ratio in a codeposited layer is shown for deposition at room temperature followed by heating of the layer to the temperature shown and for deposition at the temperature shown with no subsequent heating.

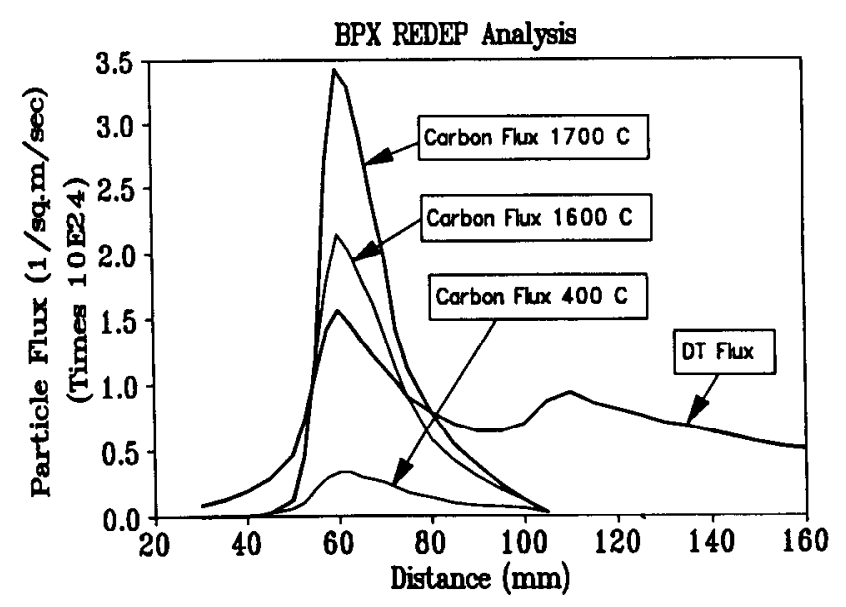

Fig. 10.4. The results of the REDEP code, showing the eroded carbon flux compared with the incident D-T flux for several different carbon surface temperatures.

flux (from DEGAS modeling ${ }^{14}$ ). It can be seen that the eroded carbon flux is greater than the incident D-T flux for the 500-MW fusion power case (where the surface temperature is $1700^{\circ} \mathrm{C}$ ). This means that the assumption of trace amounts of carbon is not correct, but the present analysis should overestimate the amount of erosion. Further research is needed to determine the effect of radiation, due to this large amount of carbon, on the edge plasma near the divertor and the ionization of the carbon within the sheath (which acts like a source of cold electrons similar to secondary electron 
TABLE 10.2. REDEP Analysis Results for BPX

\begin{tabular}{|c|c|c|c|}
\hline $\begin{array}{c}\text { Peak Divertor } \\
\text { Surface } \\
\text { Temperature }\left({ }^{\circ} \mathrm{C}\right)\end{array}$ & $\begin{array}{c}\text { Carbon Deposition } \\
\text { in Gaps } \\
\text { ( } \mathrm{g} / \text { shot) }\end{array}$ & $\begin{array}{c}\text { Peak Net Erosion } \\
\text { (nm/shot) }\end{array}$ & $\begin{array}{c}\text { Codeposited } \\
\text { Tritium }^{\mathrm{b}} \\
\text { (Ci/Shot) }^{\circ}\end{array}$ \\
\hline 400 & 0.59 & 97.4 & 89 \\
\hline 700 & 0.62 & 104.5 & 38 \\
\hline 1000 & 0.59 & 97.8 & 25 \\
\hline 1600 & 0.95 & 182.1 & 23 \\
\hline 7700 & 1.5 & 2801 & 23 \\
\hline 1800 & 1.5 & 314.7 & 23 \\
\hline
\end{tabular}

Deposition of $1 \mathrm{~g}$ of carbon is equivalent to $10^{23}$ carbon atoms being deposited.

'The tritium trapping is for all divertor plates at the local surface temperature and adjacent first wall at $400^{\circ} \mathrm{C}$.

emission). It is anticipated that these effects will lower the carbon erosion because of either reduced heat flux due to radiation or reduced sheath potential due to the electron source.

The REDEP modeling included gaps between the divertor tiles that ran in the toroidal direction. These gaps were $1 \mathrm{~mm}$ wide with $10 \mathrm{~mm}$ betwecn gaps. Most of the redeposited carbon in the high heat flux region is in the cracks between the tiles. Observations on TFTR show that this material is concentrated near the top of the cracks ${ }^{15}$ (the thickness falls exponentially with a length scale of $1.8 \mathrm{~mm}$ for a $1.5-\mathrm{mm}$ gap width in TFTR, see Fig. 10.11). To eliminate excessive ( 40 times higher) heat flux on the toroidal leading edge of tiles due to misalignment of tiles with respect to each other or due to toroidal field ripple effects, the divertor tile surfaces may be tapered (made to have a sawtooth appearance) in the toroidal direction (see Fig. 10.5). This taper of the tiles leads to additional trapping sites for redeposited carbon and codeposited D-T. This toroidal taper will increase the carbon redeposition by $10 \%$ comparcd with the values shown in Table 10.2 because additional area is created for redeposition of carbon in the high heat and particle flux zone. A taper of $h / w=0.0027$ (the design value) will result in a toroidal peaking factor of 1.12 for the heat flux. This factor is included in the 1.5 toroidal peaking factor discussed in Chap. IX.

\section{X.D. WALL CONDITIONING AND BAKEOUT}

The graphites specified for the BPX plasma-facing components absorb significant amounts of water on exposure to air. This absorbed water must be removed to obtain clean high-power plasmas. In addition, oxygen in the torus must be controlled. The administrative limits on releasable tritium inventory also require careful attention be paid to the operating temperature of the machine (see Sec. X.F). This section discusses the reasons for the specification of the $350^{\circ} \mathrm{C}$ bakeout and the operation requircments and wall conditioning techniques to be used to control oxygen.

\section{X.D.1. 350 ${ }^{\circ} \mathrm{C}$ Bakeout Requirement}

On the basis of recent experimental results from tokamaks with large graphite first-wall structures (TFTR, JET, JT-60, DIII-D, and TEXTOR), there are

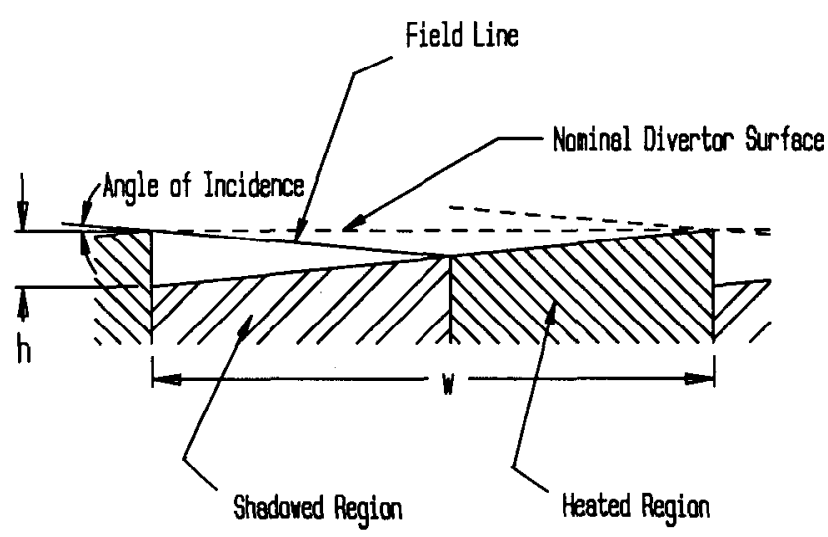

Fig. 10.5. A sketch of a cross section of the divertor tiles in the toroidal direction, showing the sawtoothing. The design value for $h / w$ is 0.0027 . The angle of incidence of the heat flux is $\sim 1.5 \mathrm{deg}$ in BPX. 
substantial advantages to be gained in being able to bake the vacuum vessel and first-wall structures of BPX up to a temperature of $350^{\circ} \mathrm{C}$. This relatively high temperature is required to remove efficiently the absorbed $\mathrm{H}_{2} \mathrm{O}$ from the graphite first-wall structures during conditioning cycles. A high operating temperature of the first wall will also reduce the trapping of tritium in codeposited layers (see Secs. X.B and X.F). Realizing this reduction of tritium retention requires that the $350^{\circ} \mathrm{C}$ wall temperature be maintained during highpower plasma operation.

The experience of JET and JT-60 with 300 to $400^{\circ} \mathrm{C}$ bakeout temperatures lends strong support for a $350^{\circ} \mathrm{C}$ bakeout requirement for impurity conditioning. Both devices can resume high-current plasma operations after air exposures with little or no additional conditioning after relatively short vessel bakeout. ${ }^{16}$ JET has turned around the device after air exposures and major in-vessel water leaks to high-current operations with 2- to 3-day bakeout periods. ${ }^{17}$ Both JET and JT- 60 have found that operation at $350^{\circ} \mathrm{C}$ reduces the cleanup time after a disruption.

\section{X.D.2. Wall Conditioning and $\mathrm{H}_{2} \mathrm{O}$ Removal}

With installation of the large-area graphite limiters and wall armor in tokamaks such as TFTR, JET, JT-60, and DIII-D, the conventional first-wall conditioning techniques following atmospheric exposures have had to be re-examined. In the case of the initial operation of TFTR with a $20-\mathrm{m}^{2}$ inner-wall bumper limiter, the usual regimens of glow discharge cleaning (GDC) and pulse discharge cleaning, in concert with $150^{\circ} \mathrm{C}$ vessel bakeout, were not able to degas sufficiently the limiter of absorbed $\mathrm{H}_{2} \mathrm{O}$ for satisfactory high-power plasma operation. ${ }^{18}$ These results are consistent with the results of laboratory measurements ${ }^{19}$ for the $\mathrm{H}_{2} \mathrm{O}$ absorption-desorption kinetics in graphite. Numerous types of nuclear-grade graphites absorb atmospheric $\mathrm{H}_{2} \mathrm{O}$ rapidly during relatively short air exposures (see Fig. 10.6). For the POCO AXF-5Q graphite used for the TFTR bumper limiter tiles, the absorption saturates at $\sim 3.5 \times 10^{20}$ molecules of $\mathrm{H}_{2} \mathrm{O}$ per gram of graphite. Thermal desorption measurements ${ }^{20}$ show that the peak desorption rates occur at $350^{\circ} \mathrm{C}$, while the desorption is negligible at graphite temperatures $<200^{\circ} \mathrm{C}$ (see Fig. 10.7). Thus, the $150^{\circ} \mathrm{C}$ bakeout temperatures in TFTR are ineffective for the complete degassing of absorbed $\mathrm{H}_{2} \mathrm{O}$, which is necessary for impurity control. This limitation was overcome in TFTR by a novel conditioning technique, dubbed disruptive discharge cleaning (DDC), which involves intentionally disrupting a series of ohmic plasmas against the bumper limiter. The energy deposition onto the bumper limiter tiles heated the tile surface to temperatures exceeding $2000^{\circ} \mathrm{C}$ (Ref. 21). The DDC technique proved effective for degassing the TFTR bumper limiter. However, because of the undesirable

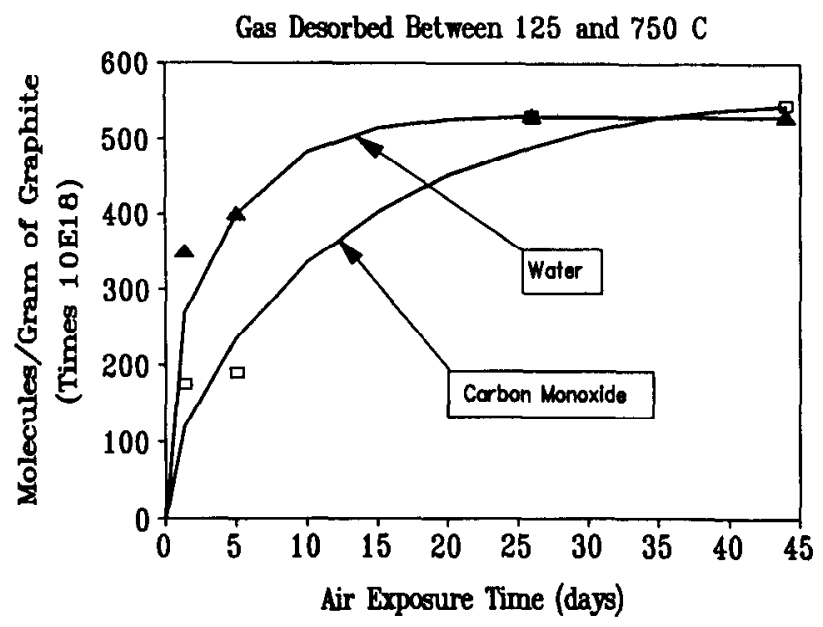

Fig. 10.6. The amount of $\mathrm{H}_{2} \mathrm{O}$ absorbed by high-temperature vacuum-outgassed graphite on exposure to atmospheric air for varying periods of time.

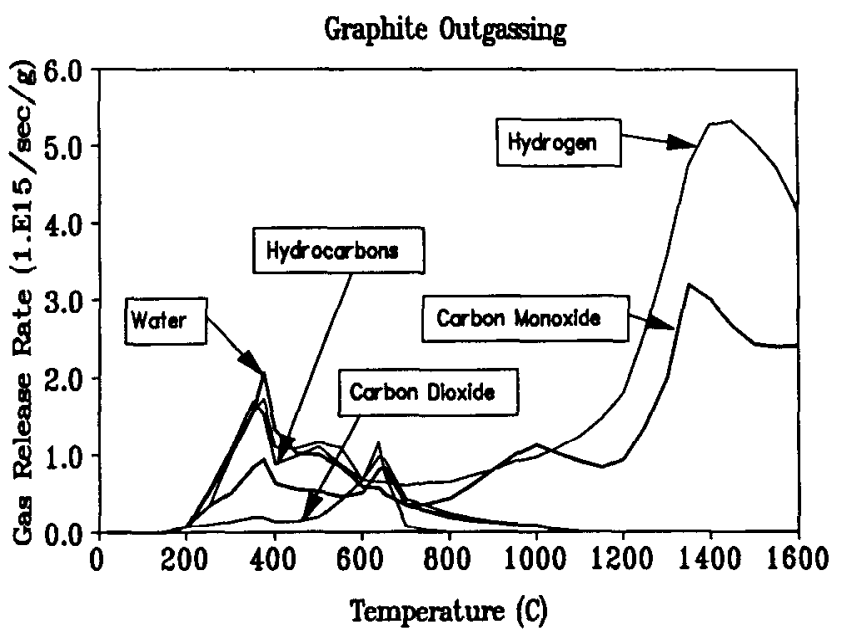

Fig. 10.7. The temperature dependence of the outgassing of several species from graphites. It can be seen that temperatures of $350^{\circ} \mathrm{C}$ are required for complete outgassing of water from graphite.

thermal and mechanical stresses induced by the disruptions on first-wall hardware and for many other reasons (e.g., time required for DDC), the technique is not recommended for use on BPX.

To prevent the migration of impurities (primarily $\mathrm{H}_{2} \mathrm{O}$ but also hydrocarbons) from first-wall structures to the vacuum vessel inner wall, where they can be released to the plasma by photon- or ion-induced desorption processes, it is necessary to use a uniform bakeout temperature of $350^{\circ} \mathrm{C}$ for the entire vacuum vessel. From the standpoint of vessel engineering, a uniform 
bakeout temperature is preferred relative to separate bakeout temperatures for the vessel and first wall to minimize thermal stresses and eliminate the need for a separate tile heating system.

\section{X.E. DISRUPTION EFFECTS ON THE PLASMA.FACING COMPONENTS}

Disruptions can be described as a two-step process in a tokamak (see Chap. $\mathrm{V}$ for a discussion of electromagnetic effects during disruptions). The plasma thermal stored energy is lost on a time scale of $-100 \mu \mathrm{s}$, with the energy going to the normal heated zone of the divertor plates or limiter. The loss of thermal energy is followed by rapid current decay, plasma motion (inward or vertical), and loss of magnetic stored energy. The current decay phase is often accompanied by the generation of energetic electrons. The extremely high heat loads resulting from these two phases cause substantial evaporation of graphite divertor plates or limiters. In this section, we estimate the effects of disruptions on the BPX plasma-facing components.

\section{X.E.1. Disruption Plasma Thermal Energy Loss Effects}

The thermal stored encrgy in the plasma for the 500-MW fusion power case is $86 \mathrm{MJ}$ (from $P_{\alpha} \times \tau_{E}$ ). The plasma thermal energy is typically lost in 100 to $1000 \mu \mathrm{s}$. The thermal stored energy is observed to be split $50 \%$ to radiation and $50 \%$ conduction to the limiter and divertor on both DIII-D (Ref. 22) and TFTR (Ref. 23). The conducted power is observed to go to the same area as the normal plasma heat flux. The width of the plasma heat flux footprint on the divertor plate is $\sim 60 \mathrm{~mm}$ on BPX. Assuming equal in/out and up/down splitting of the power (this does not alter the total erosion but will alter the details of how much local erosion takes place), the effective area for receiving the conducted thermal power is $-3.9 \mathrm{~m}^{2}$. Therefore, the average total energy per unit area deposited is $11 \mathrm{MJ} / \mathrm{m}^{2}$. Bccause the BPX divcrtor tilcs will be aligned to $\pm 0.5 \mathrm{~mm}$, we expect the disruption energy deposition will be uniform toroidally after many disruptions. The total deposited energy per unit area is the determining factor for the total evaporation, not the heat flux, as long as the heating time interval is short compared with thermal diffusion times in the material ( $<1 \mathrm{~ms}$ for pyrolytic graphite). Since the temperature of the divertor tiles is a maximum of $1700^{\circ} \mathrm{C}$ when the disruption occurs, the tiles must be first heated to sublimation temperatures $\left(>3000^{\circ} \mathrm{C}\right)$. The energy required to reach sublimation temperatures is $4.4 \mathrm{MJ} / \mathrm{m}^{2}$. The remaining energy will go into sublimation of graphite. A total of $88 \mathrm{~g} / \mathrm{m}^{2}$ (343 g total) is predicted to evaporate. The eroded thickness in the footprint area is $44 \mu \mathrm{m}$ (this would be doubled if only the outer divertor area received the disruption energy). This evaporated material will have a much longer mean-free-path than the normal carbon erosion because of the cooling of the plasma. Assuming the entire divertor area receives the evaporated material, the resulting deposits will be $\sim 10 \mu \mathrm{m}$ thick. The estimated erosion could be reduced by vapor shielding ${ }^{24}$ (radiation due to carbon absorbing plasma energy and reducing surface heat flux) or increased by particle emission ${ }^{25,26}$ that will create dust particles, not redeposited layers, that must be removed with $\mathrm{He} / \mathrm{O}$ GDC (see below). Further studies are needed to determine the effect of these two competing phenomena on the net erosion. Experiments are under way at Sandia National Laboratories and the University of New Mexico, as well as in Japan and Europe, to study the relative amounts of particle emission and erosion/redeposition.

\section{X.E.2. Disruption Magnetic Stored Energy Loss Effects} by

The magnetic stored energy in the plasma is given

$$
E_{\text {mag }}=\frac{1}{2} \mu_{0} R I_{p}^{2}\left(\frac{l_{i}}{2}\right)
$$

where $l_{i}$ is the plasma internal inductance, $R$ is the major radius, and $I_{p}$ is the plasma current. Evaluating this expression for a typical 500-MW BPX plasma gives $90 \mathrm{MJ}$ of stored energy inside the last closed flux surface (an additional $90 \mathrm{MJ}$ is stored between the plasma and the vacuum vessel wall). The total magnetic stored energy $(180 \mathrm{MJ})$ will be released during the current quench phase of the disruption. There is evidence from TFTR (Ref. 27) that $50 \%$ of this energy is carried to the plasma-facing components either as runaway electrons or thermal plasma, while the remainder is radiated to the walls of the torus. The current quench time is $-3.5 \mathrm{~ms}$ for an 11.8-MA plasma (see Chap. V). Assuming the magnetic energy is deposited in a band $0.1 \mathrm{~m}$ wide in either the top or bottom divertor or inner limiter (bccause the plasma moves either up, down, or inward), the average total energy per unit area deposited is $57.3 \mathrm{MJ} / \mathrm{m}^{2}$ (again assuming toroidal averaging over many disruptions). On TFTR, the magnetic stored energy is deposited in areas not normally heated by the plasma because of the plasma motion. Assuming a starting temperature of $400^{\circ} \mathrm{C}$ for the areas receiving the magnetic energy, the energy absorbed to reach sublimation temperature is $32.9 \mathrm{MJ} / \mathrm{m}^{2}$. The remaining $24.4 \mathrm{MJ} / \mathrm{m}^{2}$ will result in $325 \mathrm{~g} / \mathrm{m}^{2}(530 \mathrm{~g}$ total) graphite evaporation. The erosion is $\sim 160 \mu \mathrm{m}$ per disruption in the footprint area. Since the plasma is rapidly collapsing and the sublimation occurs primarily late in the current quench, we assume the graphite evaporated from the divertor will deposit nearly uniformly on the walls of the torus (pcaking factor of 2). 
The deposited graphite thickness is then $-3.2 \mu \mathrm{m}$. This analysis assumes all the magnetic stored energy conducted to the divertor plates is deposited as surface heat flux. The generation of runaway electrons during the disruption will alter the surface heating and the net erosion because of the large penetration depth of energetic electrons (see Sec. X.E.3 for a discussion of runaway electron effects).

\section{X.E.3. Runaway Electron Effects}

The loss of thermal energy during a disruption results in a flattening of the current profile and a reduction in the internal inductance. This results in a momentary negative voltage spike and an increase in the plasma current. The cooling of the plasma increases the plasma resistance, which creates a large loop voltage. The plasma current decays resistively with a large $d I / d t$. The large loop voltage leads to rapid acceleration of the tail of the electron velocity distribution. These electrons can quickly reach energies of up to hundreds of mega-electron-volts. These energetic electrons are carried by the collapsing plasma to the divertor plate or inner wall during the current quench phase of the disruption. Typically, a burst of hard $\mathrm{X}$ rays is observed during a disruption due to these energetic electrons striking the limiter or divertor tiles.

The maximum energy of the electrons is determined by a combination of bremsstrahlung, orbit shifts causing interaction with plasma-facing components, and interaction with the toroidal field ripple. Using a recent paper ${ }^{28}$ by Russo, we conclude the energy is limited by the interaction with the toroidal field ripple to energies $<200 \mathrm{MeV}$. The mean range of $200-\mathrm{MeV}$ electrons in graphite is $0.29 \mathrm{~m}$ (Ref. 29). Since both the energy loss per unit length and the range are subject to strong statistical fluctuations, ${ }^{29}$ any calculation of the energy deposition per unit volume must include both energy loss straggling and multiple scattering. The multiple scattering can lead to heating of support structures behind thin layers of graphite (especially cooling tubes for actively cooled structures). We do not anticipate such effects to be important on BPX because of the thickness of the pyrolytic graphite $(0.04 \mathrm{~m})$. A further complication is imposed by the strong toroidal magnetic field in BPX.

Codes have been developed to evaluate the interaction of energetic electrons with matter in the presence of strong magnetic fields (see, for example, Ref. 30). These codes have not yet been used to evaluate the heating of the BPX divertor or limiter by energetic electrons generated in a disruption. Russo has also developed a code to study the orbits of relativistic electrons in a diverted plasma. ${ }^{28}$ This code can be used to determine the location of the location of the runaway electron energy deposition. These codes will be used to evaluate the volume heating and possible heating of the support structure for the divertor or limiter. The ero- sion due to runaway electron heating of the plasmafacing components will be determined from the volume heating.

\section{X.E.4. Total Erosion and Disruption Recovery}

The disruption-induced total eroded layer thickness is $44 \mu \mathrm{m}$ for the thermal quench phase and $160 \mu \mathrm{m}$ for the current quench phase. These two types of erosion are not at the same spot on the divertor plates. We will not take credit for the factor of 3 reduction in net erosion due to the thermal quench not always being at the same poloidal location (this partially offsets the assumption of toroidal uniformity). We will not take credit for the three locations that will receive the current quench energy (top, bottom, and inner wall). Again, this partially offsets the assumption of toroidal uniformity. Assuming the divertor plates will have to be replaced after $25 \%(1 \mathrm{~cm})$ of the thickness has been eroded by disruptions, we will have to replace the damaged portions of the divertor after $\sim 60$ full-parameter disruptions in the current quench damage area and 230 full-parameter disruptions in the thermal quench damage area (these estimates assume toroidal averaging over many disruptions). We anticipate the erosion due to disruptions will require replacement of the divertor plates more frequently than the reduction of thermal conductivity due to neutron damage.

The total amount of carbon evaporated during a disruption is $\sim 900 \mathrm{~g}$. Since this fresh carbon layer will bury the codeposited D-T/C layers, these thick deposits must be removed when it is necessary to reduce the releasable tritium inventory. The $\mathrm{He} / \mathrm{O}$ GDC technique described in Sec. X.E.3 can be used to remove the carbon layers due to disruption erosion. For a $10-\mu \mathrm{m}$-thick layer, $\sim 28$ hours of $\mathrm{He} / \mathrm{O}$ GDC are required for removal. Hence, we will need to add about a day of $\mathrm{He} / \mathrm{O}$ cleaning, for each full-parameter disruption, to the amount needed for removing the codeposited layers. This extra cleaning time could be reduced if the tritium trapped under the disruption-deposited layers were not releasable under air exposure, but this is unlikely since all the tritium in codeposited layers as thick as $50 \mu \mathrm{m}$ is released on air exposure at $350^{\circ} \mathrm{C}$ (Ref. 31). Further research and development is needed in this area.

\section{X.F. TRITIUM RETENTION AND PARTICLE PUMPING}

Particle pumping by the plasma-facing components can result in more centrally peaked density profiles and allow for net outflow of particles from the plasma, which improves impurity control. Excessive trapping of tritium in plasma-facing components will, however, result in few discharges being allowed before the releasable tritium inventory in the torus must be reduced. The choice of the divertor and limiter tile geometry, 
operating temperature, and tritium inventory reduction technique must therefore be optimized to allow for the greatest operational flexibility.

\section{X.F.1. Graphite Wall Pumping for Particle Control}

Plasma pumping by graphite first-wall components has been observed in TFTR (Ref. 32), JET (Ref. 33), TEXTOR (Ref. 34), JT-60 (Ref. 20), and DIII-D (Ref. 20). Graphite wall pumping has proved to be a very effective means of particle control. In the case of TFTR, the plasma pumping effects are induced in the inner bumper limiter at ambient temperatures by conditioning the wall with a short series $(\sim 20)$ of lowcurrent ( 1 MA), low-density, helium-initiated ohmic discharges. The helium conditioning has been demonstrated to lower the recycling coefficient to values as low as $50 \%$. The resulting low recycling conditions are a prerequisite for the enhanced confinement, neutralbeam-heated discharges observed on TFTR (Ref. 35). The pumping capacity for neutral-beam-heated plasmas is $\sim 4.24 \times 10^{26}$ atoms (Ref. 36). Since the active area of the bumper limiter is $\sim 5 \mathrm{~m}^{2}$, the pumping capacity in TFTR is $\sim 8.5 \times 10^{21}$ atom $/ \mathrm{m}^{2}$. A portion of this wall particle pumping capacity is due to the formation of codeposited layers on the limiter surfaces (see Secs. X.C and X.F.2).

During plasma operation with graphite first-wall structures at $\sim 300^{\circ} \mathrm{C}$ in JET, TEXTOR, and JT-60, pumping effects are observed without resorting to helium conditioning. For the fluence and time interval between JET discharges, the pumping is not saturated and the inner-wall pumping capacity is used routinely to ramp down the plasma density for a nondisruptive "soft landing" at the termination of discharges. ${ }^{32}$ Such techniques will be used to control the plasma density during current rampdown on BPX (see Chap. VIII).

JT-60 has been able to produce very low density ohmic target plasmas $\left(n_{e}<8 \times 10^{18} \mathrm{~m}^{-3}\right)$ with hotwall operation. These low-density target plasmas are useful for high- $T_{i}$ discharges when neutral beam heating is used. More generally, the achievement of lowdensity target plasmas is a sign of low wall recycling. The plasma pumping effects at low tile surface temperatures $\left(<150^{\circ} \mathrm{C}\right)$ are consistent with a simple model of hydrogen retention in the near-surface region of graphite that is accessible to penetrating plasma particles. ${ }^{20}$ The pumping effects at higher temperatures are not understood but may be related to the enhanced hydrogenic diffusion and hydrogen trapping/detrapping at elevated temperatures. ${ }^{37}$ Currently, the pumping capacity at elevated temperatures and the lower temperature limit for spontaneous pumping have not been investigated. Preliminary evidence from JET (Refs. 20 and 36), JT-60 (Ref. 20), and TEXTOR (Ref. 38) suggests some wall pumping effects occur at $200^{\circ} \mathrm{C}$ but disappear at $150^{\circ} \mathrm{C}$.

With the present understanding of graphite wall pumping effects and the importance of particle control afforded by wall pumping for modifying recycling, edge profiles, and isotopic mixtures, the capability of inner-wall operation in $\mathrm{BPX}$ at $350^{\circ} \mathrm{C}$ will have substantial operational advantages, particularly as a means to reduce the plasma density at the end of standard $\mathrm{H}$-mode discharges.

\section{X.F.2. Tritium Inventory in BPX}

A number of accident scenarios examined in the BPX environmental assessment involve the possible release of tritium during an accidental breach of the BPX vacuum vessel. To assess the consequences of these potential accidents, an administrative limit of $2 \mathrm{~g}$ of releasable tritium has been set for BPX. Most of the tritium inventory remaining in the vessel will be absorbed within the graphite first-wall structure, which protects the vacuum vessel from plasma heat loads.

With the assistance of materials scientists at Sandia National Laboratories, Argonne National Laboratory, and Oak Ridge National Laboratory, tritium inventory estimates for the BPX vessel have been made, based on both measurements of hydrogen isotope (deuterium and tritium) retention in the TFTR graphite structures and laboratory studies of hydrogen isotope plasma interactions with graphite. An extensive data base ${ }^{39}$ has been gathered that is useful not only for predicting the in-vessel tritium inventory but also for providing guidance on plasma operational techniques that minimize inventory.

As a result of these tritium retention studies, three distinct mechanisms for the retention of tritium within the BPX vacuum vessel have been identified: (a) surface saturation of the plasma contacting components (i.e., limiter tiles and divertor plates); (b) diffusion into the bulk of the graphite tiles; and (c) redeposition of carbon eroded from high heat and particle flux areas onto low-flux areas with concurrent implantation of tritium into the depositing layer (codeposition trapping).

The first mechanism, the surface retention of graphite subjected to hydrogen bombardment, is well understood on the basis of numerous laboratory experiments and a simple model (the local mixing model) of hydrogen-carbon interactions. ${ }^{40}$ All forms of finegrained graphites being considered for BPX applications (including pyrolytic and CFCs) have nearly identical surface saturation levels when subjected to hydrogenic bombardment. The saturation levels are temperature dependent (similar to the results for codeposited layers shown in Fig. 10.3). The layer is saturated to a depth consistent with the range of the incident hydrogenic species. For typical first-wall impacting ion energies of 200 to $300 \mathrm{eV}$, tritium particle ranges are $20 \mathrm{~nm}$ in carbon. Because of the relatively low energy and high flux for hydrogenic species on first-wall components, the surface regions should saturate within less than one discharge in the high heat 
and particle flux areas. Because of the high surface temperatures expected in BPX, much of the divertor surface area will contain no tritium. The planned helium GDC between shots on BPX will release the surface-trapped tritium to a depth of $-5.0 \mathrm{~nm}$. Even if the helium GDC is not performed, the low level of tritium retention in the surface of the tiles has a negligible impact on total BPX tritium inventory.

The second mechanism for tritium retention that has been identified is the diffusion of tritium from the saturated surface layer to the bulk of the graphite. Diffusion of hydrogenic species is a complicated process in graphite because of the complex microstructure. Bulk tritium retention is assumed to occur uniformly throughout the carbon tiles of BPX by the process of surface diffusion and permeation along internal porosity followed by incorporation in the lattice by transgranular diffusion and trapping. Diffusion along the surface of interconnected porosity has a low activation energy $(<0.5 \mathrm{eV})$, and intragranular diffusion is characterized by a fairly high activation energy $(\sim 2 \mathrm{eV})$. Because of these activation energies, diffusion is negligible at low graphite temperatures $\left(<350^{\circ} \mathrm{C}\right)$, and retention peaks at bulk temperatures about $1200^{\circ} \mathrm{C}$ (Ref. 41). Additional trapping sites are created in the bulk of the graphite by the damage caused by the fusion neutrons. Laboratory studies ${ }^{42}$ of the tritium trapping in pyrolytic graphite due to neutron damage indicate tritium retention of 70 atomic parts per million (appm) at 0.01 displacements per atom (dpa) after 3000 full-power $(500 \mathrm{MW})$ discharges. Therefore, we expect to have $\sim 1 \mathrm{~g}$ of tritium trapped in the bulk of the tiles at the end of life of BPX. It has been shown ${ }^{43}$ that this tritium is not at risk of release during an accidental air exposure at $350^{\circ} \mathrm{C}$. Temperatures in excess of $1200^{\circ} \mathrm{C}$ are required to release the bulk trapped tritium. ${ }^{43}$ Such bulk temperatures cannot be sustained in BPX (only tile surface temperatures exceed $1200^{\circ} \mathrm{C}$ ). Hence, the bulk trapped tritium is not considered to be at risk of accidental release and need not be counted as part of the $2 \mathrm{~g}$ releasable inventory.

The major cause of tritium retention in BPX is the buildup of tritium incorporated into redeposited carbon films on all exposed surfaces of the machine, except those with high heat flux. In BPX, this mechanism can lead to significant tritium retention. For example, only $20 \mathrm{~g}$ of redeposited carbon is needed to retain $2 \mathrm{~g}$ of tritium. This codeposition process has been observed in all tokamaks using graphite limiters and in laboratory simulations of first-wall processes when graphite samples are exposed to hydrogen. ${ }^{39.44}$ Measurements of wall samples removed from TFTR show redeposited carbon films with thickncsses that are consistent with a growth rate that is linear with discharge exposure. ${ }^{45}$ Examination of limiter tiles and wall coupons from TFTR has revealed thick codeposited layers of deuterium and carbon in shadowed areas of the limiter ( $-50 \%$ of the retained deuterium) and on the sides of the cracks between tiles $(-23 \%$ of the total deuterium retained), and thinner layers on the remainder of the first-wall ( $\sim 25 \%$ of the total). A typical example of the distribution of deuterium in codeposited layers in TFTR is shown in Fig. 10.8.

Combination of the erosion/redeposition studies with data from current machines allows us to estimate the tritium retention in codeposited layers in BPX. Table 10.3 shows the expected and worst-case tritium retention in codeposited layers. The expected case is derived from the REDEP calculations and the temperature dependence of the D-T/C ratio in the films. The worst-case scenario assumes all the redeposited carbon traps D-T at the maximum rate of $0.25 \mathrm{D}-\mathrm{T} / \mathrm{C}$ at $350^{\circ} \mathrm{C}$. The worst case is consistent with the measured tritium retention (40\%) on TFTR and DIII-D, which have lower density and much cooler tiles. The required D-T fueling rate can be calculated from the particle pumping and the assumed recycling coefficients. The results are shown in Table 10.4 (see Chap. VIII for more discussion of fueling).

The tritium trapped in codeposited layers has been shown to be at risk of release during an accidental air exposure. ${ }^{31}$ Figure 10.9 shows the fraction of tritium remaining in a codeposited layer at various temperatures. It can be seen that all the tritium is released at the $350^{\circ} \mathrm{C}$ operating temperature of BPX. Some of the films studied were from TFTR and up to $50 \mu \mathrm{m}$ thick.

\section{X.F.3. Tritium Inventory Management}

Carbon film deposition onto the plasma-facing components represents a reversible tritium retention mechanism. Intentional carburization of plasma-facing components using $\mathrm{CH}_{4} / \mathrm{H}_{2}$ glow discharges is a welldocumented wall conditioning technique for tokamaks. ${ }^{36}$ The deposited carbon films can be removed by plasma etching with exposure to $\mathrm{He} / \mathrm{O}$ glow dis-

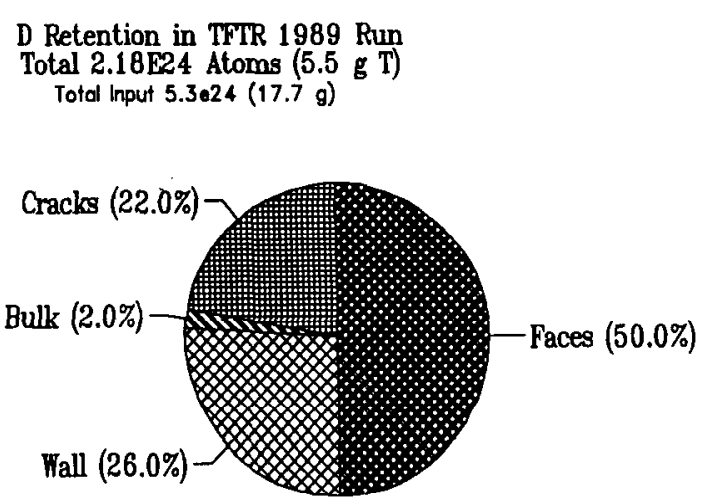

Fig. 10.8. The distribution of deuterium retention in TFTR after a typical high-power run period. Note that most of the retained deuterium is in codeposited layers on the surfaces of the limiter or the first wall. 
Ulrickson et al. IMPURITY CONTROL AND MATERIALS PHYSICS

TABLE 10.3. Tritium Retention in BPX

\begin{tabular}{|c|c|c|}
\hline & Expected & Pessimistic \\
\hline$\tau_{E}$ & $0.85 \mathrm{~s}$ & $0.85 \mathrm{~s}^{\mathrm{2}}$ \\
\hline$\tau_{p}$ & $1.7 \mathrm{~s}^{\mathrm{b}}$ & $0.85 \mathrm{~s}^{\mathrm{b}}$ \\
\hline $\begin{array}{l}\text { Recycling coefficient } \\
{\left[\tau_{p}^{*} \equiv \tau_{f} /(I-R)\right]}\end{array}$ & $<0.96^{c}$ & 0.66 \\
\hline $\begin{array}{l}\text { Net tritium outflow } \\
\text { (5-s high-power pulse) }\end{array}$ & $>65 \mathrm{Ci}^{\mathrm{c}}$ & $1000 \mathrm{Ci}$ \\
\hline Tritium retained during burn & $65 \mathrm{Ci}^{\mathrm{c}}$ & $400 \mathrm{Ci}^{\mathrm{dec}}$ \\
\hline Tritium in plasma at shutdown & $500 \mathrm{Ci}^{\mathbf{r}}$ & $500 \mathrm{Ci}$ \\
\hline Tritium retained during shutdown & $0-75 \mathrm{Ci}^{4}$ & $0-100 \mathrm{Ci}^{\mathrm{d} s}$ \\
\hline Density ramp phase retention & $11 \mathrm{Ci}^{\mathrm{h}}$ & $140 \mathrm{Ci}^{1}$ \\
\hline Total retention/shot & $76-151 \mathrm{Ci}$ & $540-640 \mathrm{Ci}$ \\
\hline Shots to reach $20 \mathrm{kCi}$ limit & $132-264$ & $32-38$ \\
\hline
\end{tabular}

${ }^{2}<n>/ \tau_{E}$ depends weakly on $C_{\varepsilon}$ and on the operating density, which means $\tau_{E}$ and hence $\tau_{p}$ are nearly constant for a variety of conditions.

Tritium provided by pellet injection.

${ }^{\circ}$ Calculated from saturation of codeposited carbon at $T<-800^{\circ} \mathrm{C}$.

'Based on TFTR/JET experience.

Calculated from saturation of all codeposited carbon.

'Assumes $\left\langle n_{\rangle}\right\rangle=3.0 \times 10^{20} / \mathrm{m}^{3}$.

50 to $100 \%$ removal of codeposited layer built on inner wall during shutdown, via helium GDC between shots.

Assumes 7-s density ramp time, $R=0.94$, and retention of 0.2 .

'Assumes $\boldsymbol{R}=\mathbf{0 . 6 6}$ and retention of $\mathbf{0 . 2}$.

Maximum design capability is 16 full-field shot/day.

TABLE 10.4. Required D-T Fueling Rates for BPX Based on Particle Pumping by Codeposition

\begin{tabular}{|l|c|c|c|c|}
\hline & \multicolumn{2}{|c|}{ Expected } & Pessimistic \\
\hline Phase & Buildup & Burn & Buildup & Burn \\
\hline$<\mathrm{n}_{\mathrm{\gamma}}>\left(10^{20} / \mathrm{m}^{3}\right)$ & 1.5 & 3.0 & 1.5 & 3.0 \\
\hline $\mathrm{d}\left(\mathrm{N}_{\mathrm{Dr}}\right) / \mathrm{dt}\left(10^{21} / \mathrm{s}\right)$ & 2.79 & 0. & 2.79 & 0. \\
\hline $\begin{array}{l}\mathrm{D}-\mathrm{T} \text { fueling rate required } \\
\left(10^{21} / \mathrm{s}\right)\end{array}$ & 3.11 & 1.31 & 6.81 & 8.04 \\
\hline $\mathrm{D}-\mathrm{T}$ pumping rate $\left(10^{21} / \mathrm{s}\right)$ & 0.33 & 0.13 & 4.02 & 8.04 \\
\hline Duration (s) & 7.0 & 5.0 & 7.0 & 5.0 \\
\hline
\end{tabular}

charges. ${ }^{46}$ A typical example of the removal rate for $\mathrm{He} / \mathrm{O}$ GDC is shown in Fig. 10.10. The removal rate is limited by the pumping speed of the torus. Removal rates of $0.1 \mathrm{~nm} / \mathrm{s}$ have been observed. The removal is due to atomic oxygen created by the glow. The removal efficiency is $1.0 \pm 0.01 \mathrm{C} / \mathrm{O}$ (Ref. 47). In the pessimistic case, we expect to be able to remove the codeposited layer from a day's operation during an 


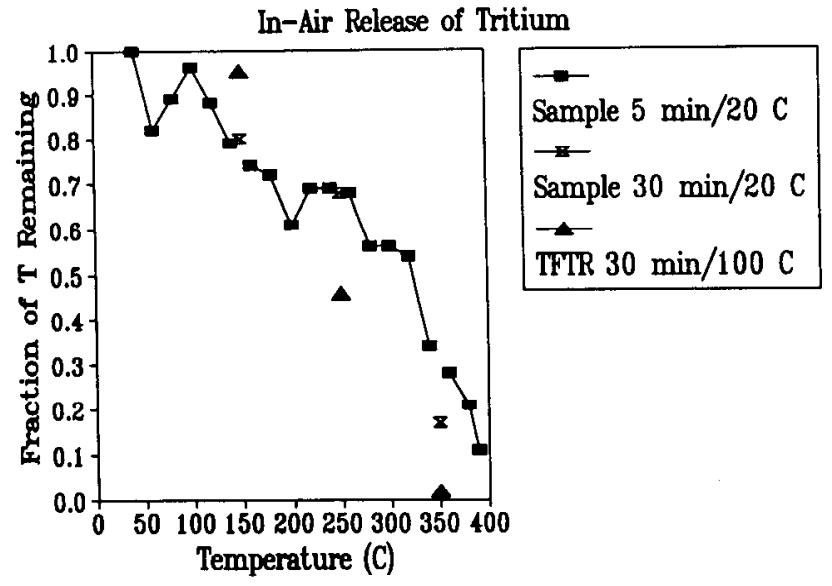

Fig. 10.9. The percentage of the original D-T trapped in a codeposited layer of D-T and carbon on exposure of the layer to air at various temperatures. It can be seen that all of the D-T is released below $350^{\circ} \mathrm{C}$.

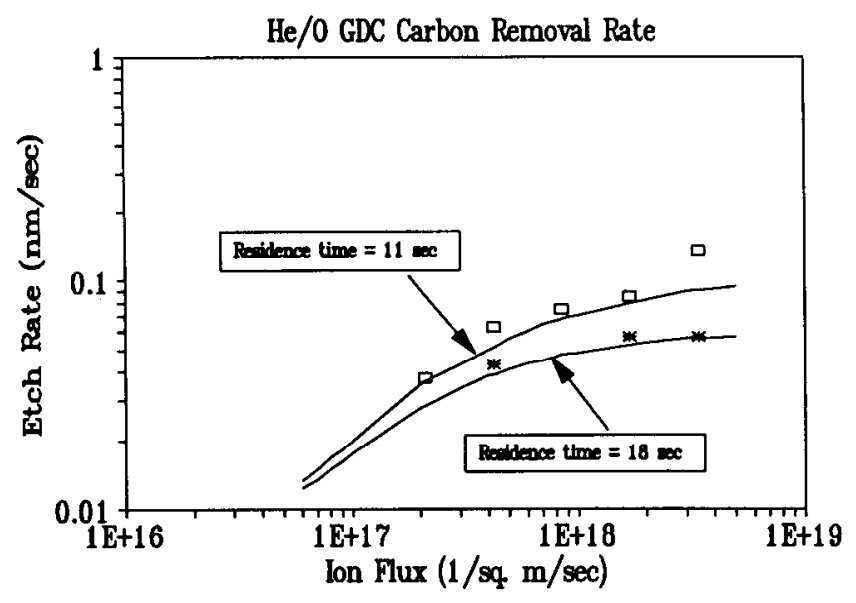

Fig. 10.10. The carbon film removal rate of $\mathrm{He} / \mathrm{O} \mathrm{GDC}$ measured as a function of the ion flux to the wall. The clamping of the rate at high flux is due to the vacuum pumping time constant for removal of the products from the chamber.

overnight cleaning activity. In the expected case, we expect to remove the codeposited layers using $\mathrm{He} / \mathrm{O}$ GDC in the off-weeks.

We expect $\mathrm{He} / \mathrm{O}$ GDC to be very effective for controlling the tritium inventory in BPX. However, removal of codeposited films within crevices and cracks between tiles has not yet been demonstrated. Laboratory experiments will be conducted on codeposited layers on TFTR limiter tiles to determine the removal efficiency in cracks between tiles. We expect the $\mathrm{He} / \mathrm{O}$ GDC to be effective in the cracks because the atomic oxygen should penetrate down the cracks as effectively

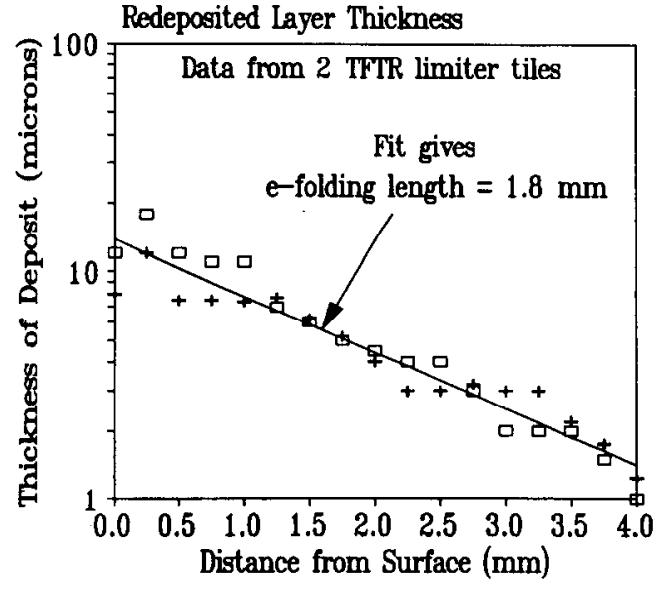

Fig. 10.11. The variation of the thickness of redeposited carbon on the sides of the cracks between the TFTR bumper limiter tiles. The $e$-folding length for the thickness is $5 \mathrm{~mm}$ (the crack width is $\sim 1.5 \mathrm{~mm}$ ).

as the carbon atoms that are deposited on the sides of the crack. In addition, the thickness of the deposits on the sides of the cracks falls off exponentially with distance (see Fig. 10.11). Therefore, the thickest deposits are the easiest to remove. The amount of residual oxygen left in the machine after $\mathrm{He} / \mathrm{O}$ cleaning has not been studied. This will also be studied using the TFTR tiles in the laboratory. These studies will also help to quantify the accuracy with which the end point of the removal of the codeposited layers can be measured. Experiments are planned for TFTR to determine the effect of $\mathrm{He} / \mathrm{O}$ GDC on machine operation. However, even if the removal efficiency was only 0.9 and all the unreacted oxygen remained in the torus, we expect that outgassing at $350^{\circ} \mathrm{C}$ will remove at least $50 \%$ of the remaining oxygen. We will use boronization to control any oxygen that is not outgassed. Only $50 \mathrm{~nm}$ of boron would be required to control all the residual oxygen. After boronization on TFTR, a water leak of at least 1000 Torr $\cdot \ell$ into the torus caused no interruption of plasma operation ${ }^{48}$ (a similar leak before boronization resulted in a one-week downtime for conditioning).

A typical operating sequence for the expected tritium inventory buildup rate is shown in Fig. 10.12. Since the bulk inventory is not at risk of release, the allowed inventory buildup is always $2 \mathrm{~g}(20 \mathrm{kCi})$. Since the $\mathrm{He} / \mathrm{O}$ removal proceeds at a rate determined by the time constant of the pumping system $(\sim 0.1 \mathrm{~nm} / \mathrm{s})$, the amount of time required for recovery of the releasable inventory depends on how many shots are required to reach the allowed 2-g releasable inventory. The expected rate of inventory accumulation ( $\sim 200$ shots) will require 60 to 120 hours of cleaning during nonoperational weeks. For the pessimistic rate of accumulation, only 5 to 10 hours of cleaning are required to 


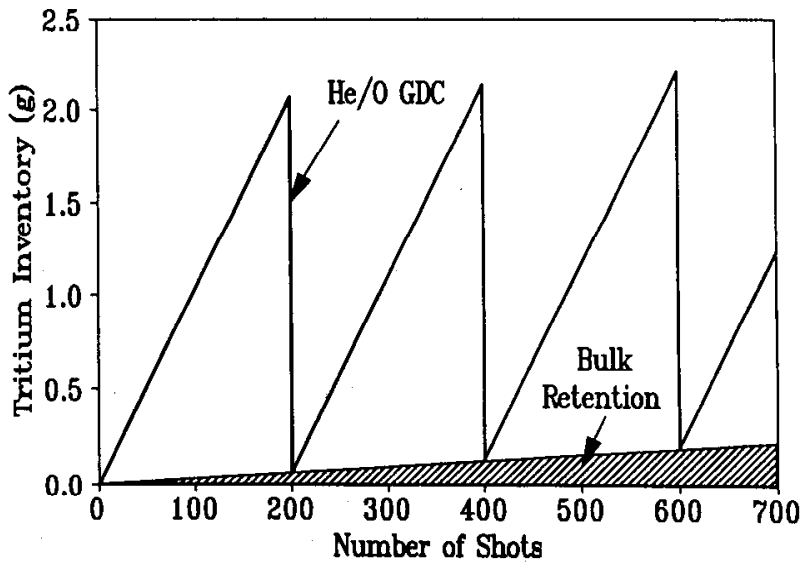

Fig. 10.12. A typical BPX operational sequence for tritium retention in codeposited layers. About $48 \mathrm{~h}$ of $\mathrm{He} / \mathrm{O} \mathrm{GDC}$ is required to remove the releasable tritium inventory in this case. The bulk trapped tritium is not releasable.

remove the codeposited layer after each day's run. We have confidence that the $\mathrm{He} / \mathrm{O}$ GDC will allow us to manage the releasable tritium inventory without significantly affecting the operation of BPX.

In summary, the current maximum estimated invessel tritium inventory for BPX is $\mathbf{3}$. Of this $3 \mathrm{~g}$ total, $1 \mathrm{~g}$ is absorbed in the bulk of the graphite and is not at risk, and $2 \mathrm{~g}$ is in the codeposited layers on the tile surfaces and is potentially at risk in an up-to-air accident. He/O GDC will be used to remove the codeposited layers after $\sim 200$ shots (expected) or overnight (worst case). Boronization can be used if desired to control any remaining oxygen from the cleaning.

\section{ACKNOWLEDGMENTS}

This work was supported by U.S. Department of Energy under contract DE-AC02-761-CHO-3073. The authors wish to thank the members of the Deuterium/Tritium Materials Physics Group for their efforts in characterizing tritium retention on existing machine such as TFTR and DIII-D.

\section{REFERENCES}

1. J. HAINES, Internal BPX Memo \#B-901107-ESI-04 (Nov. 1990).

2. M. ULRICKSON, J. Nucl. Mater., $176 \& 177$ (in press).

3. R. TAYLOR, B. T. KELLEY, and K. E. GILCHRIST, J. Phys. Chem. Solids, 30, 2251 (1969).

4. G. ENGLE, Private Communication (1990).
5. J. N. BROOKS, H. F. DYLLA, A. E. PONTAU, and K. L. WILSON, Fusion Technol., 19, 1095 (1991).

6. J. ROTH, J. BOHDANSKY, and W. OTTENBERGER, IPP 9/26, Max-Planck Institut für Plasmaphysik (May 1979).

7. E. VIETZKE et al., J. Nucl. Mater., 145-147, 443 (1987).

8. V. PHILLIPS, E. VIETZKE, and H. TRINKAUS, presented at Int. Conf. Fusion Reactor Materials, Kyoto, Japan, December 1989, to be published in J. Nucl. Mater.

9. J. ROTH, J. BOHDANSKY, and K. L. WILSON, $J$. Nucl. Mater., 111 \& 112, 775 (1982).

10. L. BREWER and A. W. SEARCY, Ann. Rev. Phys. Chem., 7, 259 (1956).

11. J. N. BROOKS, Phys. Fluids, B2, 1858 (1990).

12. B. L. DOYLE, W. R. WAMPLER, and D. K. BRICE, J. Nucl. Mater., 103 \& 104, 513 (1981).

13. D. A. BOWERS, Internal BPX Memo B-901206-ESI08 (Dec. 1990).

14. D. STOTLER, B2 Code Runs, Unpublished.

15. W. L. HSU, B. E. MILLS, A. B. EHRHARDT, and Y. C. SUN, J. Vac. Sci. Technol., A7, 1065 (1989).

16. IAEA Workshop on the Physics Operations of Tokamaks, Princeton, New Jersey, September 1987.

17. K. J. DEITZ, JET Project, Private Communication (1989).

18. H. F. DYLL $\Lambda$ et al., J. Nucl. Mater., 145/146, 48 (1987).

19. A. E. PONTAU and D. H. MORSE, J. Nucl. Mater., 141/143, 124 (1986).

20. A. E. PONTAU et al., J. Vac. Sci. Technol., A4, 1193 (1986).

21. H. F. DYLLA et al., J. Nucl. Mater., 145-147, 48 (1987).

22. T. HINO et al., J. Nucl. Mater., 121, 337 (1984).

23. H. F. DYLLA et al., J. Nucl. Mater., 155-157, 15 (1988).

24. C. D. CROESSMAN, G. L. KULCINSKI, and J. B. WHITLEY, J. Nucl. Mater., 128 \& 129, 816 (1984).

25. C. D. CROESSMAN et al., J. Nucl. Mater., 155-157, 278 (1988). 
26. H. BRINKSCHULTE, E. DEKSNIS, and A. S. BRANSDEN, J. Nucl. Mater., 155-157, 261 (1988).

27. M. ULRICKSON, presented at the IAEA Workshop on Disruptions, Vienna, Austria, July 1987.

28. A. RUSSO, Nucl. Fusion, 31, 117 (1991).

29. M. J. BERGER and S. M. SELTZER, NBS Circular 577, National Bureau of Standards (1964).

30. J. A. HALBLEIB and T. A. MELHORN, SAND 840573, Sandia National Laboratories (Nov. 1984).

31. R. A. CAUSEY, W. L. CHRISMAN, and W. L. HSU, J. Vac. Sci. Technol., A7, 1078 (1989).

32. H. F. DYLLA, Nucl. Fusion, 17, 1221 (1987).

33. S. A. COHEN et al., Proc. 14th European Conf. Controlled Fusion and Plasma Physics, Madrid, Spain (1987).

34. J. WINTER, H. G. ESSER, F. WAELBROECK, and P. WEINHOLD, Proc. 14th European Conf. Controlled Fusion and Plasma Physics, Madrid, Spain (1987).

35. J. D. STRACHAN et al., Phys. Rev. Lett., 58, 1004 (1987).

36. H. F. DYLLA et al., J. Nucl. Mater., 162-164, 128 (1989).
37. J. EHRENBERG, Proc. IEA Workshop on Hydrogen Retention in Tokamak Walls and Limiters, Princeton, New Jersey, July 1987.

38. J. WINTER, J. Nucl. Mater., 145/147, 131 (1987).

39. H. F. DYLLA and K. L. WILSON, Eds., PPPL-2523/ SAND 88-8212, Princeton Plasma Physics Laboratory/ Sandia National Laboratories.

40. B. L. DOYLE, W. R. WAMPLER, D. K. BRICE, and S. T. PICRAUX, J. Nucl. Mater., 93/94, 551 (1980).

41. R. A. CAUSEY, M. I. BASKES, and K. L. WILSON, J. Vac. Sci. Technol., A4, 1189 (1986).

42. W. R. WAMPLER, B. L. DOYLE, R. A. CAUSEY, and K. L. WILSON, J. Nucl. Mater., $176 \& 177$ (in press).

43. R. A. CAUSEY, W. R. WAMPLER, and D. WALSH, J. Nucl. Mater., 176 \& 177 (in press).

44. W. L. HSU and R. A. CAUSEY, J. Vac. Sci. Technol., A5, 2768 (1987).

45. W. R. WAMPLER et al., J. Vac. Sci. Technol., A6, 2111 (1988).

46. W. L. HSU, J. Vac. Sci. Technol, A7, 1047 (1989).

47. W. LANGER, Private Communication (1989).

48. H. F. DYLLA et al., J. Nucl. Mater., 176 \& 177 (in press). 